\title{
LncRNAs regulate the cytoskeleton and related Rho/ROCK signaling in cancer metastasis
}

\author{
Yanyan Tang ${ }^{1,2+}$, Yi He ${ }^{1,2+}$, Ping Zhang ${ }^{2,6+}$, Jinpeng Wang ${ }^{2}$, Chunmei Fan², Liting Yang ${ }^{2}$, Fang Xiong ${ }^{5}$,

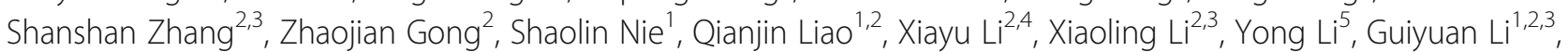 \\ Zhaoyang Zeng ${ }^{1,2,3}$, Wei Xiong ${ }^{1,2,3^{*}}$ and Can Guo ${ }^{1,2,3^{*}}$
}

\begin{abstract}
Some of the key steps in cancer metastasis are the migration and invasion of tumor cells; these processes require rearrangement of the cytoskeleton. Actin filaments, microtubules, and intermediate filaments involved in the formation of cytoskeletal structures, such as stress fibers and pseudopodia, promote the invasion and metastasis of tumor cells. Therefore, it is important to explore the mechanisms underlying cytoskeletal regulation. The ras homolog family (Rho) and Rho-associated coiled-coil containing protein serine/threonine kinase (ROCK) signaling pathway is involved in the regulation of the cytoskeleton. Moreover, long noncoding RNAs (IncRNAs) have essential roles in tumor migration and guide gene regulation during cancer progression. LnCRNAs can regulate the cytoskeleton directly or may influence the cytoskeleton via Rho/ROCK signaling during tumor migration. In this review, we focus on the regulatory association between IncRNAs and the cytoskeleton and discuss the pathways and mechanisms involved in the regulation of cancer metastasis.
\end{abstract}

Keywords: Long noncoding RNA, Cytoskeleton, Rho/ROCK signaling, Cancer metastasis

\section{Background}

Cell migration requires cytoskeletal reorganization, which plays a critical role in cancer metastasis [1, 2]. In particular, some classical signaling pathways are involved during cytoskeletal reorganization, such as the ras homolog family (Rho) and Rho-associated coiled-coil protein kinase (ROCK) signaling pathway [3, 4].

Approximately $75 \%$ of human genomic DNA can be transcribed into RNA, but only $2-3 \%$ of the genes encode a protein; therefore, in the entire transcriptome, the proportion of noncoding RNAs is far higher than the proportion of protein-coding mRNAs [5]. Among the former, lncRNA is a transcript longer than 200 nucleotides and cannot code for a protein; it can play an important role in the process of tumor metastasis through

\footnotetext{
* Correspondence: xiongwei@csu.edu.cn; guocde@csu.edu.cn

${ }^{\dagger}$ Equal contributors

'Department of Colorectal Surgery, Hunan Cancer Hospital and The Affiliated Cancer Hospital of Xiangya School of Medicine, Central South University, Changsha, Hunan, China

Full list of author information is available at the end of the article
}

multiple mechanisms [6]. The abnormal expression of lncRNAs is related to the poor prognosis of patients with cancer. Studies have revealed that the lncRNA AFAP1-AS1 promotes the invasion and migration of nasopharyngeal carcinoma (NPC) cells by stimulating stress fiber formation [7]. The lncRNA Pvt1 oncogene (PVT1) is related to poor prognosis by inhibiting apoptosis in colorectal cancers [8]. PVT1 is an indicator of poor prognosis for gastric cancer and promotes cell proliferation by regulating the epigenetic expression of p15 and p16 [9]. Depletion of the lncRNA urothelial cancer associated 1 (UCA1) induces radiosensitivity and decreases proliferative capacity [10]. Thus, IncRNAs can promote tumor cell invasion, migration, proliferation, and radiosensitivity and inhibit tumor cell apoptosis, thereby accelerating tumor progression, predisposing cancer patients to distant metastasis, and resulting in poor prognosis.

LncRNAs can directly interact with cytoskeletal proteins to change the three-dimensional structure of cells and can regulate the cytoskeleton through the Rho/ROCK signaling pathway. Therefore, the interactions among lncRNAs, 
Rho/ROCK signaling, and the cytoskeleton underlie the ability of a cell to become motile, eventually leading to tumor migration $[7,11]$. This review describes the current knowledge about the mechanisms underlying cytoskeleton reprogramming, followed by discussion of the roles of lncRNAs. The interaction between lncRNAs and cell migration suggests new therapeutic targets in cancer metastasis.

\section{Cytoskeletal reorganization and cancer cell movement}

The cytoskeleton refers to the structure of the protein fiber network in eukaryotic cells. It plays an important role in the maintenance of cell shape, cell movement, transportation of substances in cells, and cytokinesis. Eukaryotic cells contain three main types of cytoskeletal filaments: microfilaments, microtubules, and intermediate filaments [12].

Microfilaments are also called actin filaments. They are approximately $7 \mathrm{~nm}$ in diameter and are composed of two strands of spiral fibers, which are formed by actin polymerization [13]. The basic unit of the microfilament is globular actin (also known as G-actin). Actin monomers, one after another, link to form an actin chain, and two actin chains twist around each other to form a strand of microfilament [14]. This actin polymer is filamentous actin (F-actin). The main functions of microfilaments are the formation of stress fibers, cell movement, and cytokinesis [15].

The structure and function of microfilaments is regulated by a variety of proteins. These proteins are associated with the microfilament and are known as microfilamentassociated proteins; some examples include capping proteins, Arp2/3 complex, cofilin, etc. [16, 17].

The capping protein can selectively block one end of filamentous F-actin, resulting in the shortening or extension of the microfilament, which is vital for the high motility of cancer cells [18]. Research has shown that the capping protein scinderin (SCIN) regulates actin and then participates in the migration of tumor cells. In addition, the silencing of SCIN in vitro and in vivo significantly inhibits the formation of filopodia and reduces the migratory ability of gastric cancer cells [19]. The Arp $2 / 3$ complex is an actin-related protein and can nucleate the microfilament (nucleation) [20]. The entire complex can be bound to the microfilament to allow new microfilaments to be generated. In tumor cells, the function of the Arp2/3 complex is related to the movement of the lamellipodia [21]. Cofilin is a family of actin-binding proteins that disassemble microfilaments [22]. The depolymerization of cofilin can change the adhesion between cells and the extracellular matrix and ultimately promote cell migration [23, 24]. Fascin is a type of actin-bundling protein [25]. The primary functions of fascin are related to adhesion and the formation of filopodia in the movement of cancer cells [26].

Microtubules have a diameter of $25 \mathrm{~nm}$ [27]. They are composed of $\alpha$ and $\beta$ tubulin subunits that form tubulin dimers [28]. Microtubules function by resisting compression and bending to maintaining cell morphology [29]. During cell migration, microtubules, together with the attached dynein, may release a signal to promote focal adhesion depolymerization [30].

The diameter of an intermediate filament is $10 \mathrm{~nm}$, which is the size between microtubules and microfilaments. This structure is the most stable cytoskeletal component and plays a major role in supporting the cell [31]. Microtubules and microfilaments are assembled by spherical proteins, and intermediate fibers are assembled by long, rod-shaped proteins [32]. The intermediate filament proteins can be divided into six types based on similarities in amino acid sequence and protein structure: acidic and basic keratins, vimentin, neurofilaments, nuclear lamin, and nestin. Vimentin is the most widely distributed of all intermediate filament proteins [33-35]. Vimentin regulates cell adhesion molecules and other components and is involved in tumor cell adhesion, the epithelial-mesenchymal transition (EMT), migration, and invasion [36-38].

When invading the dense extracellular matrix, cancer cells need to have a high degree of deformability. The network structure of fibers that is composed of microfilaments and various microfilament binding proteins under the plasma membrane is called the cell cortex [39]. The cell cortex can push the cell membrane to form protrusions, including lamellipodia, filopodia, and invadopodia [40].

Lamellipodia are at the front end of a migrating cell and contain actin filament branching structures that form an actomyosin branch, which is more mature, and then extend to form lamellar protrusions. Lamellipodia usually help the cell move forward and can also drive random or continuous cell migration that is associated with the migratory phenotype of tumor cells [41]. Lamellipodia generate the driving force for cell migration [42].

Filopodia are small fingerlike cell protrusions. They contain an F-actin parallel fascicular arrangement. Filopodia are formed by actin polymerization, extending to the front end of the cell, and are especially prominent in migrating cells [43]. The contractility of filopodia is weaker than that of lamellipodia. Nonetheless, in some highly invasive tumor cells, lamellipodia are not formed, but a large number of filopodia can be observed [44, 45]. Therefore, filopodia may be associated with the invasive phenotype of tumor cells.

The invadopodia is rich in actin microfilaments and adhesion proteins, such as integrin, focal adhesion kinase (FAK), and vinculin, and forms a ring around the actin 
bundles [13]. The formation of invadopodia releases a variety of matrix metalloproteinases (MMPs) and degrades the extracellular matrix (ECM) to promote cell invasion [46]. ECM degradation mediated by invadopodia can also generate cell traction, which helps tumor cells to invade new sites [47].

Interestingly, fast moving cells mainly form lamellipodia, while nearly immobile cells have lamellipodia and filopodia. Lamellipodia, filopodia, and invadopodia can remodel the cytoskeleton by changing microfilaments, microtubules, and intermediate filaments. In the process of tumor cell migration, cytoskeletal reorganization is regulated by non-coding RNA and signaling pathways [48, 49] (Fig. 1).

\section{LncRNAs regulate the cytoskeleton in cancer}

lncRNAs can affect the migration of tumor cells by regulating the cytoskeleton or related proteins [50-52]. The most direct evidence comes from the function of a lncRNA called "downregulated in hepatocellular carcinoma" (Dreh). The expression of Dreh is lower in cancer tissues than that in normal tissues. Patients with high expression of Dreh show a low recurrence rate and long survival time. Dreh can inhibit cell migration, and further research showed that
Dreh binds to and inhibits intermediate filaments and prevents cancer cell metastasis by changing the cytoskeletal structure and cell morphology [53].

Another cytoskeleton-related lncRNA is LINC00152, which also known as cytoskeleton regulator RNA. The expression of LINC00152 is upregulated in tissue samples from various cancers. For example, Chen et al. showed that LINC00152 expression is increased in 60 human lung adenocarcinoma tissue samples relative to paired normal tissues [54]. Müller et al. reported the upregulation of LINC00152 in pancreatic cancer tissue [55]. LINC00152 is associated with a poor prognosis of tongue carcinoma with invasion and metastasis and is overexpressed in a variety of tumors, such as breast cancer, lung cancer, gastric cancer, liver cancer, gallbladder cancer, and colorectal cancer. Therefore, LINC00152 can serve as a new tumor marker [54, 56-61]. In the breast cancer cell line MDAMB-231, LINC00152 regulates target genes involved in cytoskeletal remodeling, including tubulin tyrosine ligase, Rho guanosine triphosphatase (GTPase) Rhobtb3, and plakophilin 4 [60]. An Ingenuity Pathway Analysis revealed that some of the target genes of LINC00152 are closely related to the cell spreading pathway, including actin polymerization-driven processes, the Rho family of

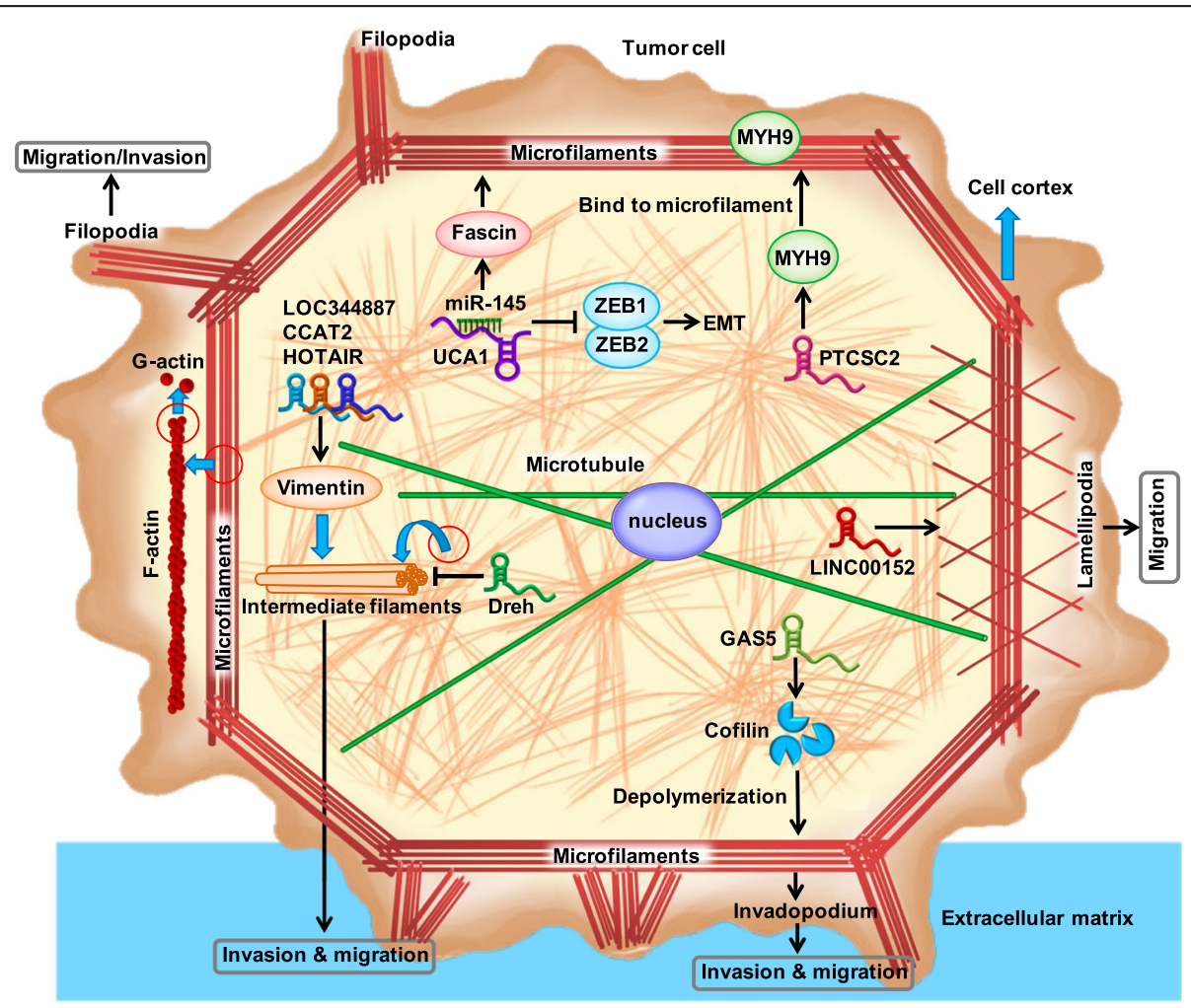

Fig. 1 LncRNAs regulate the cytoskeleton and related proteins in cancer. LncRNAs can directly regulate the cytoskeleton and related proteins in various cancers. The IncRNA Dreh can inhibit the expression of intermediate filaments by binding to them and can prevent metastasis by changing the cytoskeletal structure and morphology of cancer cells. The IncRNA LINC00152 is involved in cytoskeletal remodeling and affects F-actin reorganization. LOC344887, CCAT2, and HOTAIR regulate vimentin. PTCSC2 regulates actin filaments via binding to MYH9 
GTPase promoters, and the mTORC2 complex [62, 63]. Therefore, in experiments that knocked down LINC00152 expression using a locked nucleic acid or that used fluorescently labeled F-actin, cells treated with LINC00152 are smaller, rounder, show actin reorganization, a reduction in stress fibers, and the appearance of thick actin fibers in the cortex compared with the control group [60]. In addition, according to the literature, LINC00152 may affect $\mathrm{F}$-actin reorganization by regulating the expression of Golgi phosphoprotein 3 (GOLPH3) [64].

Vimentin is responsible for maintaining the integrity of the cytoskeleton and cell shape [65]. Many lncRNAs have been shown to affect vimentin, including HOX transcript antisense RNA (HOTAIR), LOC344887, and colon cancer associated transcript 2 (CCAT2). HOTAIR is relevant to small cell lung cancer invasiveness by suppressing cell adhesion-related genes such as astrotactin 1 (ASTN1) and protocadherin alpha 1 (PCDHA1) [66]. In cervical carcinoma, HOTAIR promotes the migration and invasiveness of HeLa cells by regulating the expression and organization of vimentin [51]. The inhibition of HOTAIR significantly promotes the collapse of the vimentin intermediate-filament network to lead to a decrease in cell migration and invasion [51].

Vimentin is a marker of EMT that appears during cancer metastasis. LOC344887 increases the migration and invasion of gallbladder cancer cells. In particular, LOC344887 leads to EMT by increasing the protein expression of vimentin [67]. Similarly, the IncRNA CCAT2 promotes hepatocellular cancer metastasis by positively regulating vimentin and inducing EMT [68]. Vimentin intermediate filaments are strongly involved in cell shape, focal adhesion, and motility by altering these characteristics during EMT [69].

The lncRNA papillary thyroid cancer susceptibility candidate 2 (PTCSC2) has one unspliced isoform and several spliced isoforms, all of which show thyroidspecific expression. Myosin-9 (MYH9) interacts with the IncRNA PTCSC2 [70]. Further studies have shown that MYH9 binds to the FOXE1 promoter region, PTCSC2, to regulate FOXE1 promoter activity. MYH9 participates in the generation of cell polarity, cell migration, cell-cell adhesion processes, and cytoskeleton maintenance by binding to actin filaments [71].

The expression of the lncRNA growth arrest-specific 5 (GAS5) is downregulated in glioma tissues. GAS5 inhibits the migration and invasion of U87 and U251 human glioma cell lines [72]. Mechanistically, overexpression of GAS5 increases the expression of plexin $\mathrm{C} 1$, which encodes a member of the plexin family. Plexins are transmembrane receptors for semaphorins, which regulate cell motility and migration by downregulating miR-222 [72]. Furthermore, plexin $\mathrm{C} 1$ targets cofilin by inducing cofilin inactivation rather than by decreasing the cofilin amount.
Cofilin stimulates microfilament disassembly to promote cell mobility during tumor migration and invasion $[72,73]$. This finding may indirectly explain why GAS5 inhibits the migration and invasion of glioma cells by reorganizing the cytoskeleton. Nevertheless, the mechanism needs further study.

The IncRNA UCA1 is upregulated in bladder cancer and induces EMT, migration, and invasion of bladder cancer cells. Mechanistically, UCA1 regulates bladder cancer cell migration and invasion by miR-145 and its target genes actin-bundling protein fascin and zinc finger E-box binding homeobox 1 and 2 (ZEB1/2) [74]. UCA1 is a direct target of hsa-miR-145 by interacting with the miR145 binding site at exons 2 and 3 of UCA1. UCA1 mediates bladder cancer migration and invasion through the miR145-ZEB1/2-fascin pathway [74]. Fascin localizes along the entire length of all filopodia. RNA interference of fascin reduced the number of filopodia, and the remaining filopodia had abnormal morphology and loosely bundled actin organization $[75,76]$.

Thus, different lncRNAs can affect the migration of tumor cells via affecting various components of the cytoskeleton and associated proteins (Fig. 1 and Table 1).

\section{Rho/ROCK signaling in cytoskeletal reorganization}

Many receptor proteins activated in the plasma membrane can initiate cytoskeletal reorganization; the signals are all mediated by the RhoGTP family and the downstream effector ROCK, which compose the Rho/ROCK signaling pathways $[77,78]$. The most studied Rho GTPases can be subdivided into three classes: Rho (RhoA, RhoB, and RhoC), Rac (Rac1, Rac2, and Rac3), and cell division cycle 42 (Cdc42). Other less studied GTPases include RhoD and RhoE [79-81].

Rho aggregates actin and myosin to form stress fibers and focal adhesion complex assembly [82, 83]. RhoA is present at the cell membrane when it is active [84]. RhoA regulates the generation of actomyosin bundles, stress fibers, focal adhesions, and lamellipodia [85]. RhoB is found in endosomes and at the plasma membrane. The role of RhoB in cancer progression remains unknown, and it responds to specific signals in the tumor microenvironment [84]. RhoC modulates phagosome formation by actin cytoskeletal remodeling via mDia1 [86].

Rac primarily promotes the formation of lamellipodia and invadopodia. Rac1 localizes mainly to the plasma membrane and drives the formation of lamellipodia and invadopodia [87]. Rac2 is critical for cell adhesion to intercellular adhesion molecule-1 (ICAM-1) and for immunological synapse formation [88]. Rac3 is critical for integrating the adhesion of invadopodia to the extracellular matrix (ECM) to allow invadopodia to degrade the ECM [89]. 
Table 1 Summary of IncRNAs regulate cytoskeletons in cancer

\begin{tabular}{|c|c|c|c|}
\hline LncRNAs & $\begin{array}{l}\text { Cytoskeletons and } \\
\text { associated protein }\end{array}$ & Functions & Refs \\
\hline Dreh & Intermediate filament & $\begin{array}{l}\text { Prevent cancer cell migration through changing the cytoskeleton } \\
\text { structure and cell morphology }\end{array}$ & [34] \\
\hline LINC00152 & F-actin & LINC00152 affects F-actin by regulating the expression of GOLPH3 & {$[41,45]$} \\
\hline LOC344887, CCAT2, HOTAIR & Vimentin & LOC344887, CCAT2 and HOTAIR regulate the expression of vimentin & {$[32,55,57]$} \\
\hline PTCSC2 & MYH9 & PTCSC2 binds MYH9 to regulate cytoskeleton & [59] \\
\hline GAS5 & cofilin & $\begin{array}{l}\text { GAS5 suppressed glioma cell growth, migration and invasion by } \\
\text { targeting miR-222. miR-222 induced cofilin dephosphorylation by } \\
\text { silencing PLXNC1 gene }\end{array}$ & [61] \\
\hline UCA1 & FSCN1 & $\begin{array}{l}\text { UCA1 promotes bladder cancer cell migration and invasion by the } \\
\text { hsa-miR-145-ZEB1/2- FSCN1 pathway }\end{array}$ & [66] \\
\hline
\end{tabular}

Cdc42 promotes the formation of filopodia and induces cell migration and metastasis [90]. Other less studied GTPases, such as RhoE, can bind to ROCK1 and inhibit the activity of ROCK1 [91, 92]. Phosphoinositide dependent kinase 1 activates ROCK1 by opposing the inhibition of RhoE and then promotes cell motility [92].

The ROCK family includes two members, ROCK1 and ROCK2 [93], which are encoded by two different genes $[94,95]$. ROCK1 plays a key role in the formation of stress fibers, and this isoform is mainly responsible for rigidity-dependent invadopodia activity through actomyosin contractility [96, 97]. ROCK2 is important for phagocytosis, cell contraction and stabilizing the cytoskeleton [78, 97, 98].

Rho/ROCK signals can regulate the development and balance the formation of lamellipodia, filopodia and invadopodia, and these signals promote the degradation of the extracellular matrix [99].

Rac1 promotes actin polymerization during lamellipodium formation through the WAVE complex and subsequent activation of the Arp2/3 complex [100].

Cdc42 activates the formin protein mDia2 to regulate actin nucleation and elongation of microfilaments $[101,102]$. Cdc42 can also activate N-WASP to stimulate the Arp2/3 to induce actin polymerization. The straight parallel alignment of microfilaments form filopodia [99].

RhoA and RacC play important roles during the formation of invadopodia. RhoA activates $\mathrm{mDia} 2$ and further induces the formation of linear actin bundles to result in the elongation of invadopodia [103]. ET-1 triggers increased binding to ETAR and promotes the formation of the $\beta$ arrestin/PDZ-RhoGEF signaling complex, which activates ROCK/LIMK/cofilin through RhoC activity and generates actin remodeling and invadopodia formation [104].

In addition to regulating the formation of invadopodia, Cdc42 plays an important role in the trafficking of MMPs to the invadopodia. For example, Cdc42 induced IQGAP1 binding at invadopodia to traffic MT1-MMP and MMP14 by vesicles $[105,106]$. ROCK expression increases during pancreatic cancer progression, and ROCK consequently increases the phosphorylation of MLC2. pMLC2 causes actomyosin contraction and then induces the release of the stromelysin MMP10 and the collagenase MMP13. Eventually, MMPs promote extracellular matrix remodeling to enable invasive growth [94] (Fig. 2).

\section{LncRNAs regulate Rho/ROCK signaling during tumor migration}

LncRNAs can regulate cancer cell migration by targeting Rho/ROCK signaling and include metastasis-associated lung adenocarcinoma transcript 1 (MALAT1), actin filament associated protein 1 antisense RNA1 (AFAP1AS1), and maternally expressed 3 (MEG3) [7, 107, 108]. The lncRNA MALAT1 reduces the protein expression levels of RhoA, ROCK1, and ROCK2, indicating that MALAT1 may promote osteosarcoma cell migration by the RhoA/ROCK pathway; then, MALAT1 increases the number of actin stress fibers in osteosarcoma cells [107]. Another study suggested that MALALT1, miR-1, and cdc42 are competitive endogenous RNAs (ceRNAs) in breast cancer cells [108]. MALAT1 can bind and inhibit miR-1; miR-1 can bind to the 3'UTR of cdc42 and decrease the expression of cdc42 to induce the migration and invasion of breast cancer cells [108].

Our research group has found that the lncRNA AFAP1-AS1 leads to the loss of stress fiber formation in nasopharyngeal carcinoma by influencing the expression of RhoA/Rac2 signaling and F-actin polymerization [7]. Zhang et al. also found that increased expression of AFAP1-AS1 significantly correlates with pathological staging and lymph-vascular space invasion in patients with hepatocellular carcinoma via inhibition of RhoA/ Rac2 signaling. Overall, AFAP1-AS1 may promote NPC and hepatocellular carcinoma metastases through RhoA/ Rac2 signaling [109].

Wang et al. demonstrated that downregulated lncRNA MEG3 is associated with lymph node metastasis in primary thyroid cancer. Mechanistically, MEG3 suppresses 


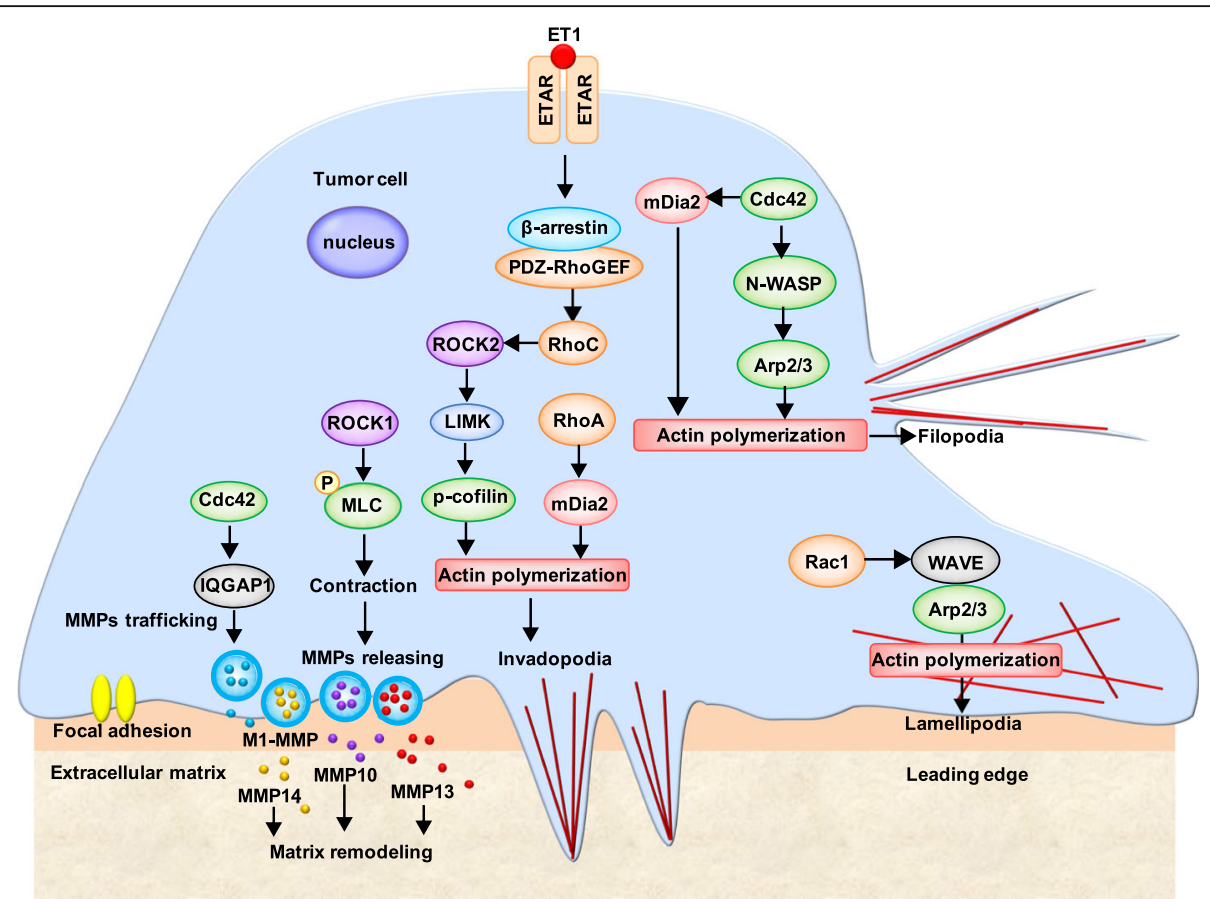

Fig. 2 Rho/ROCK signaling in cytoskeleton reorganization. Rho/ROCK signaling regulates the formation of lamellipodia, filopodia and invadopodia and the release of MMPs

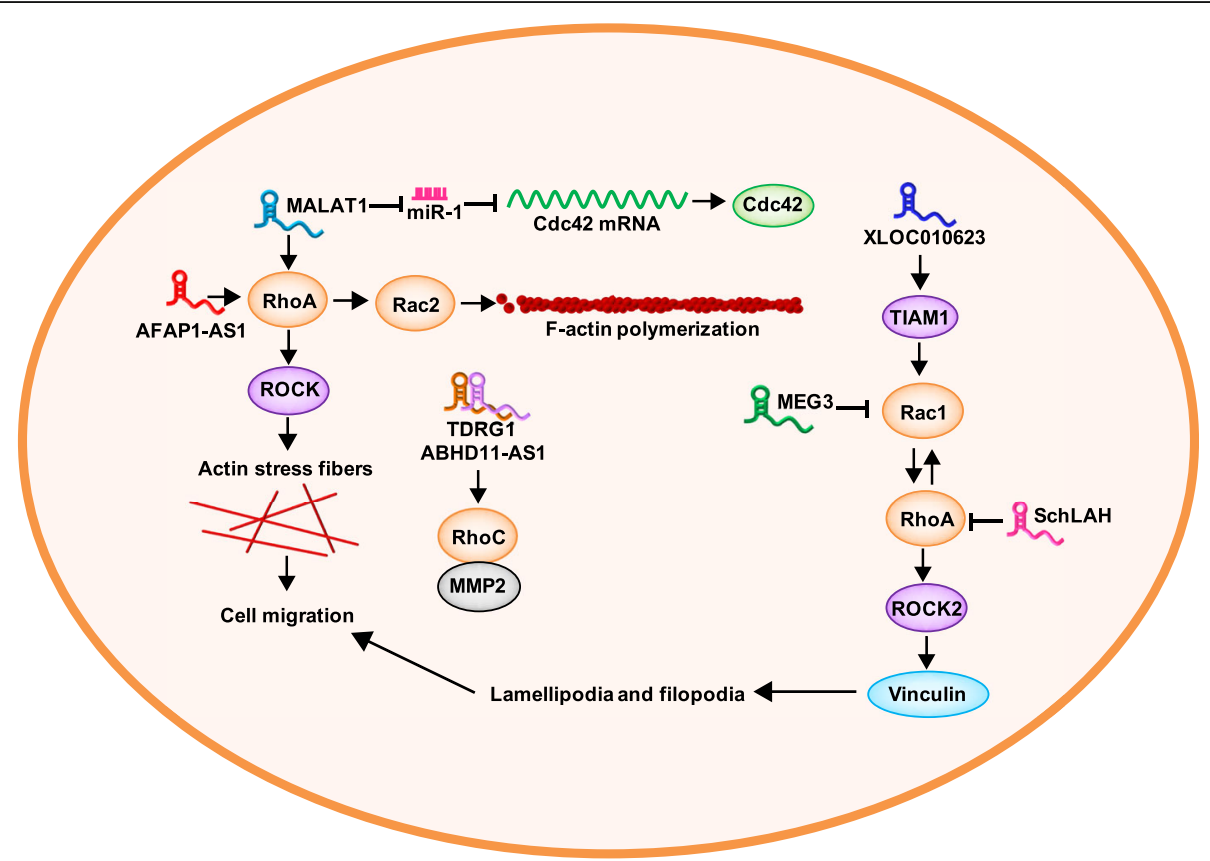

Fig. 3 LncRNAs regulate Rho/ROCK signaling in cancer metastasis. MALAT1 facilitates the metastasis of osteosarcoma though the RhoA/ROCK pathway and can act as ceRNA to inhibit miR-1 by targeting Cdc42, thereby inducing breast cancer cell metastasis. XLOC010623 activates the TIAM1/Rac1 and RhoA/ROCK2 signaling pathways and then increases the expression of vinculin, leading to the migration of adipose tissue-derived stem cells. SchLAH physically inhibits the migration of HCC cells through RhoA and Rac1. MEG3 downregulates Rac1 expression and is linked to primary thyroid cancer with lymph node metastasis. AFAP1-AS1 might promote NPC and HCC metastasis through RhoA/Rac2 signaling. TDRG1 induces RhoC expression and tumor progression in EOC. ABHD11-AS1 can directly bind to RhoC and upregulate the expression of its downstream molecule MMP2, thus increasing the metastatic ability of EOC 
Table 2 Summary of IncRNAs regulate the Rho/ROCK signaling in cancer

\begin{tabular}{|c|c|c|c|}
\hline LncRNAs & Rho/Rho-associated protein & Functions & Refs \\
\hline MALAT1 & RhoA, ROCK1 and ROCK2 & $\begin{array}{l}\text { MALAT1 facilitates the metastasis of osteosarcoma though } \\
\text { RhoA/ROCK pathway }\end{array}$ & {$[103]$} \\
\hline MALAT1 & Cdc42 & $\begin{array}{l}\text { MALAT1 plays a role of } \mathrm{Cdc} 42 \text { ceRNA and induces migration } \\
\text { by blocking miR-1 in breast cancer cells }\end{array}$ & [104] \\
\hline AFAP1-AS1 & RhoA/Rac2 & $\begin{array}{l}\text { AFAP1-AS1 might promote tumor metastasis through regulation } \\
\text { of tumor cell adhesion and mobility via RhoA/Rac2 signaling }\end{array}$ & [7] \\
\hline MEG3 & Rac1 & $\begin{array}{l}\text { MEG3 is a novel suppressor of migration and metastasis by } \\
\text { targeting Rac1 gene }\end{array}$ & [107] \\
\hline XLOC 010623 & Rac1, RhoA and ROCK2 & $\begin{array}{l}\text { Tetrahedral DNA nanostructures (TDNs) suppressed the } \\
\text { transcription of XLOC010623, and activated the TIAM1/Rac1 } \\
\text { and RhoA/ROCK2 to promote cell migration }\end{array}$ & [108] \\
\hline SchLAH & RhoA and Rac1 & $\begin{array}{l}\text { SchLAH suppressed migration of HCC cells through } \\
\text { downregulating RhoA and Rac1 }\end{array}$ & [110] \\
\hline TDRG1 & RhoC & TDRG1 induced RhoC expression in epithelial ovarian carcinoma & [111] \\
\hline ABHD11-AS1 & RhoC & ABD11-AS1 can bind to RhoC directly in epithelial ovarian carcinoma & [112] \\
\hline
\end{tabular}

the expression of Rac1 through a specific site in the 3' UTR [110]. Vinculin is another motility-associated protein that is synthesized in migrating cells, and vinculindeficient cells extend unstable lamellipodia and filopodia. The IncRNA XLOC010623 activates the TIAM1/Rac1 and RhoA/ROCK2 signaling pathways, increases the expression of vinculin and causes the migration of adipose tissue-derived stem cells [111]. The lncRNA SchLAH physically inhibits the migration of HCC cells through RhoA and Rac1 [112]. The regulatory mechanism of the lncRNAs ABHD11-AS1 and TDRG1 are similar; they both induce the expression of RhoC and MMP during tumor progression [113, 114].

LncRNAs are involved in cancer metastasis mainly through reorganizing the cytoskeletal structure and by regulating the expression of molecules in the RhoA/ ROCK pathway to result in an increased number of actin cytoskeleton fibers, stress fiber formation, formation of lamellipodia and filopodia, tumor cell adhesion, and angiogenesis. The regulatory mechanism includes ceRNA and direct binding to RAC1 and other molecules in the Rho/ROCK pathway. Understanding these relationships may provide insights into human lncRNA regulation, cytoskeletal structure, cell migration, and cancer metastasis. We present various lncRNAs in Fig. 3 and Table 2 and describe many lncRNAs that regulate tumor metastasis through cytoskeletal remodeling via the Rho/ROCK pathway. lncRNAs may be a promising target for future cancer therapy.

\section{Conclusions}

From a physics viewpoint, the development of a tumor is a biological process driven by mechanics, which is regulated by the biochemical signaling pathways of tumor cells. For example, changes in cellular mechanical properties can activate signal transduction pathways. In this review, we associate the physical movement of the cell with Rho/ROCK signaling and discuss the regulatory involvement of lncRNAs, which are significant for future research.

Many studies have shown that Rho/ROCK-mediated cytoskeletal regulation plays a key part in cancer metastasis. External factors stimulate the transition of normal cells to tumor cells. The activity of the intracellular Rho signal increases, the arrangement of cytoskeleton fibers changes, and then cell morphology is affected. In contrast, in the Rho/ROCK pathway, lncRNA-regulated specific molecules are less frequent, and we do not understand their specific mechanisms of action. Therefore, the mechanism of Rho/ROCK regulation by lncRNA and their relationship to metastasis remain to be studied.

Targeting Rho/ROCK signaling-associated IncRNAs could be useful for inhibiting the migration of cancer cells and may be a new target for the treatment of cancer metastasis. Some questions need to be addressed. For example, do lncRNAs regulate other signaling pathways that are associated with the cytoskeleton? How can the cytoskeleton be targeted via lncRNAs for clinical cancer treatment? With the development of lncRNA research and technologies for measuring cell movements, the relationship between lncRNAs and cell migration and invasion in tumor metastasis can be uncovered.

\footnotetext{
Abbreviations

AFAP1-AS1: actin lament associated protein 1 antisense RNA1; ASTN1: astrotactin 1; CCAT2: colon cancer associated transcript 2; CDC42: cell division cycle 42; ceRNA: competitive endogenous messenger RNA; Dreh: downregulated in hepatocellular carcinoma; EMT: epithelial mesenchymal transition; Factin: filamentous actin; FSCN1: fascin actin-bundling protein 1; GAS5: Growth ArrestSpecific 5; GTPase: Rho guanosine triphosphatase; HOTAIR: Hox transcript antisense intergenic RNA; LIMK: LIM kinase; LncRNAs: long noncoding RNAs; MALAT1: metastasis-associated lung adenocarcinoma transcript 1; MEG3: maternally expressed 3; MLC: myosin light chain; MYH9: Myosin-9; MYPT1: myosin phosphatase 1; NPC: nasopharyngeal carcinoma; PAK: p21 activated kinase; PCDHA1: protocadherin alpha 1; PTCSC2: papillary thyroid cancer
} 
susceptibility candidate 2; PVT1: Pvt1 oncogene; RhoA: Ras homolog family member A; ROCK: Rho-associated coiled-coil containing protein serine/threonine kinases; TDRG1: testis development-related gene 1; UCA1: urothelial cancer- associated 1

\section{Acknowledgments}

Not applicable

\section{Funding}

This work was supported by the National Natural Science Foundation of China (81472531, 81572787, 81672683, 81772928, 81702907, and 81772901), Scientific Research Projuct of the Health and Family Planning Commission of Hunan Province (B20180809) and the Natural Science Foundation of Hunan Province (2018JJ3634, 2017SK2105, 2016JC2035, and 2015JJ1022).

\section{Availability of data and materials}

Not applicable

\section{Authors' contributions}

YT, YH and PZ wrote the manuscript and drew the figs. JW, CF and LY collected the related papers and created the Tables. FX, SZ, ZG, SN and QL helped to revise the manuscript. $\mathrm{XL}, \mathrm{XL}, \mathrm{YL}, \mathrm{GL}$ and $\mathrm{ZZ}$ participated in the design of the review. WX and CG designed and revised the manuscript. All the authors read and approved the final version of the review.

\section{Ethics approval and consent to participate}

Not applicable

\section{Consent for publication}

Not applicable

\section{Competing interests}

The authors declare that they have no competing interests.

\section{Publisher's Note}

Springer Nature remains neutral with regard to jurisdictional claims in published maps and institutional affiliations.

\section{Author details}

${ }^{1}$ Department of Colorectal Surgery, Hunan Cancer Hospital and The Affiliated Cancer Hospital of Xiangya School of Medicine, Central South University, Changsha, Hunan, China. ${ }^{2}$ The Key Laboratory of Carcinogenesis and Cancer Invasion of the Chinese Ministry of Education, Cancer Research Institute, Central South University, Changsha, Hunan, China. ${ }^{3}$ The Key Laboratory of Carcinogenesis of the Chinese Ministry of Health, Xiangya Hospital, Central South University, Changsha, Hunan, China. ${ }^{4}$ Hunan Key Laboratory of Nonresolving Inflammation and Cancer, Disease Genome Research Center, The Third Xiangya Hospital, Central South University, Changsha, Hunan, China. ${ }^{5}$ Department of Cancer Biology, Lerner Research Institute, Cleveland Clinic, Cleveland, OH, USA. ${ }^{6}$ School of Electronics and Information Engineering, Hunan University of Science and Engineering, Yongzhou, Hunan, China.

Received: 4 September 2017 Accepted: 20 March 2018 Published online: 04 April 2018

\section{References}

1. Xiang T, Fan Y, Li C, Li L, Ying Y, Mu J, Peng W, Feng Y, Oberst M, Kelly K, Ren G, Tao Q. DACT2 silencing by promoter CpG methylation disrupts its regulation of epithelial-to-mesenchymal transition and cytoskeleton reorganization in breast cancer cells. Oncotarget. 2016;7:70924-35.

2. Leduc C, Etienne-Manneville S. Regulation of microtubule-associated motors drives intermediate filament network polarization. J Cell Biol. 2017;216:1689-703.

3. Yu FX, Guan KL. The hippo pathway: regulators and regulations. Genes Dev. 2013:27:355-71

4. Halon A, Donizy P, Surowiak P, Matkowski R. ERM/rho protein expression in ductal breast cancer: a 15 year follow-up. Cell Oncol (Dordr). 2013;36:181-90.

5. Gong Z, Zhang S, Zeng Z, Wu H, Yang Q, Xiong F, Shi L, Yang J, Zhang W, Zhou Y, Zeng Y, Li X, Xiang B, Peng S, Zhou M, Li X, et al. LOC401317, a p53-regulated long non-coding RNA, inhibits cell proliferation and induces apoptosis in the nasopharyngeal carcinoma cell line HNE2. PLoS One. 2014:9:e110674.

6. Yu J, Liu Y, Gong Z, Zhang S, Guo C, Li X, Tang Y, Yang L, He Y, Wei F, Wang Y, Liao Q, Zhang W, Li X, Li Y, Li G, et al. Overexpression long noncoding RNA LINC00673 is associated with poor prognosis and promotes invasion and metastasis in tongue squamous cell carcinoma. Oncotarget. 2017:8:16621-32

7. Bo H, Gong Z, Zhang W, Li X, Zeng Y, Liao Q, Chen P, Shi L, Lian Y, Jing Y, Tang K, Li Z, Zhou Y, Zhou M, Xiang B, Li X, et al. Upregulated long noncoding RNA AFAP1-AS1 expression is associated with progression and poor prognosis of nasopharyngeal carcinoma. Oncotarget. 2015;6:20404-18.

8. Takahashi Y, Sawada G, Kurashige J, Uchi R, Matsumura T, Ueo H, Takano Y, Eguchi H, Sudo T, Sugimachi K, Yamamoto H, Doki Y, Mori M, Mimori K. Amplification of PVT-1 is involved in poor prognosis via apoptosis inhibition in colorectal cancers. Br J Cancer. 2014;110:164-71.

9. Kong $R$, Zhang EB, Yin DD, You LH, Xu TP, Chen WM, Xia R, Wan L, Sun M, Wang ZX, De W, Zhang ZH. Long noncoding RNA PVT1 indicates a poor prognosis of gastric cancer and promotes cell proliferation through epigenetically regulating p15 and p16. Mol Cancer. 2015;14:82.

10. Fotouhi Ghiam A, Taeb S, Huang X, Huang V, Ray J, Scarcello S, Hoey C, Jahangiri S, Fokas E, Loblaw A, Bristow RG, Vesprini D, Boutros P, Liu SK. Long non-coding RNA urothelial carcinoma associated 1 (UCA1) mediates radiation response in prostate cancer. Oncotarget. 2017:8:4668-89.

11. Zeng Z, Bo H, Gong Z, Lian Y, Li X, Li X, Zhang W, Deng H, Zhou M, Peng S, Li G, Xiong W. AFAP1-AS1, a long noncoding RNA upregulated in lung cancer and promotes invasion and metastasis. Tumour Biol. 2016;37:729-37.

12. Killilea AN, Csencsits R, Le E, Patel AM, Kenny SJ, Xu K, Downing KH. Cytoskeletal organization in microtentacles. Exp Cell Res. 2017;357:291-8.

13. Albiges-Rizo C, Destaing O, Fourcade B, Planus E, Block MR. Actin machinery and mechanosensitivity in invadopodia, podosomes and focal adhesions. J Cell Sci. 2009;122:3037-49.

14. Wei F, Tang L, He Y, Wu Y, Shi L, Xiong F, Gong Z, Guo C, Li X, Liao O Zhang W, Ni Q, Luo J, Li X, Li Y, Peng C, Chen X, Li G, Xiong W, Zeng Z. BPIFB1 (LPLUNC1) inhibits radioresistance in nasopharyngeal carcinoma by inhibiting VTN expression. Cell Death Dis. 2018;9(4):432

15. Yang $Y$, Li M, Sun X, Zhou C, Wang Y, Wang L, Chen L, Liang Z, Zhu L, Yang $H$. The selective cytotoxicity of DSF-cu attributes to the biomechanical properties and cytoskeleton rearrangements in the normal and cancerous nasopharyngeal epithelial cells. Int J Biochem Cell Biol. 2017;84:96-108.

16. Dugina V, Alieva I, Khromova N, Kireev I, Gunning PW, Kopnin P. Interaction of microtubules with the actin cytoskeleton via cross-talk of EB1-containing +TIPs and gamma-actin in epithelial cells. Oncotarget. 2016;7:72699-715.

17. Paavilainen VO, Bertling E, Falck S, Lappalainen P. Regulation of cytoskeletal dynamics by actin-monomer-binding proteins. Trends Cell Biol. 2004;14:386-94.

18. Terry SJ, Dona F, Osenberg P, Carlton JG, Eggert US. Capping protein regulates actin dynamics during cytokinetic midbody maturation. Proc Natl Acad Sci U S A. 2018:115:2138-43.

19. Liu JJ, Liu JY, Chen J, Wu YX, Yan P, Ji CD, Wang YX, Xiang DF, Zhang $X$ Zhang P, Cui YH, Wang JM, Bian XW, Qian F. Scinderin promotes the invasion and metastasis of gastric cancer cells and predicts the outcome of patients. Cancer Lett. 2016:376:110-7.

20. Molinie N, Gautreau A. The Arp2/3 regulatory system and its deregulation in Cancer. Physiol Rev. 2018:98:215-38.

21. Dimchev G, Steffen A, Kage F, Dimchev V, Pernier J, Carlier MF, Rottner K. Efficiency of lamellipodia protrusion is determined by the extent of cytosolic actin assembly. Mol Biol Cell. 2017;28:1311-25.

22. Bugyi B, Carlier MF. Control of actin filament treadmilling in cell motility. Annu Rev Biophys. 2010;39:449-70.

23. Andrianantoandro E, Pollard TD. Mechanism of actin filament turnover by severing and nucleation at different concentrations of ADF/cofilin. Mol Cell. 2006:24:13-23.

24. Maciver SK, Hussey PJ. The ADF/cofilin family: actin-remodeling proteins. Genome Biol. 2002;3:reviews3007.

25. Heinz LS, Muhs S, Schiewek J, Grub S, Nalaskowski M, Lin YN, Wikman H Oliveira-Ferrer L, Lange T, Wellbrock J, Konietzny A, Mikhaylova M, Windhorst S. Strong fascin expression promotes metastasis independent of its F-actin bundling activity. Oncotarget. 2017:8:110077-91.

26. Wolff JR, Stuke K, Missler M, Tytko $H$, Schwarz P, Rohlmann A, Chao TI. Autocellular coupling by gap junctions in cultured astrocytes: a new view on cellular autoregulation during process formation. Glia. 1998;24:121-40. 
27. Chandra Mangalhara K, Manvati S, Saini SK, Ponnusamy K, Agarwal G, Abraham SK, Bamezai RN. ERK2-ZEB1-miR-101-1 axis contributes to epithelial-mesenchymal transition and cell migration in cancer. Cancer Lett. 2017:391:59-73.

28. Lv X, He C, Huang C, Hua G, Wang Z, Remmenga SW, Rodabaugh KJ, Karpf AR, Dong J, Davis JS, Wang C. G-1 inhibits breast cancer cell growth via targeting colchicine-binding site of tubulin to interfere with microtubule assembly. Mol Cancer Ther. 2017;16(6):1080-91.

29. Zhang Y, Xia M, Jin K, Wang S, Wei H, Fan C, Wu Y, Li X, Li X, Li G, Zeng Z, Xiong $W$. Function of the $c-$ Met receptor tyrosine kinase in carcinogenesis and associated therapeutic opportunities. Mol Cancer. 2018;17(1):45.

30. Carter BZ, Mak PY, Wang X, Yang H, Garcia-Manero G, Mak D, Mu H, Ruvolo V, Qiu Y, Coombes K, Zhang N, Ragon B, Weaver DT, Pachter JA, Kornblau S, Andreeff M. Focal adhesion kinase as a potential target in AML and MDS. Mol Cancer Ther. 2017;16(6):1133-44.

31. He $Y$, Jing $Y$, Wei $F$, Tang $Y$, Yang $L$, Luo J, Yang $P, N i$, Pang J, Liao $Q$, Xiong F, Guo C, Xiang B, Li X, Zhou M, Li Y, Xiong W, Zeng Z, Li G. Long non-coding RNA PVT1 predicts poor prognosis and induces radioresistance by regulating DNA repair and cell apoptosis in nasopharyngeal carcinoma. Cell Death Dis. 2018;9(2):235.

32. Helfand BT, Chang L, Goldman RD. The dynamic and motile properties of intermediate filaments. Annu Rev Cell Dev Biol. 2003;19:445-67.

33. Wei F, Wu Y, Tang L, He Y, Shi L, Xiong F, Gong Z, Guo C, Li X, Liao Q, Zhang W, Zhou M, Xiang B, Li X, Li Y, Li G, Xiong W, Zeng Z. BPIFB1 (LPLUNC1) inhibits migration and invasion of nasopharyngeal carcinoma by interacting with VTN and VIM. Br J Cancer. 2018;118(2):233-47.

34. Lopez CG, Saldanha O, Huber K, Koster S. Lateral association and elongation of vimentin intermediate filament proteins: a time-resolved light-scattering study. Proc Natl Acad Sci U S A. 2016;113:11152-7.

35. Fogl C, Mohammed F, Al-Jassar C, Jeeves M, Knowles TJ, Rodriguez-Zamora P, White SA, Odintsova E, Overduin M, Chidgey M. Mechanism of intermediate filament recognition by plakin repeat domains revealed by envoplakin targeting of vimentin. Nat Commun. 2016;7:10827.

36. Costigliola N, Ding L, Burckhardt CJ, Han SJ, Gutierrez E, Mota A, Groisman A, Mitchison TJ, Danuser G. Vimentin fibers orient traction stress. Proc Natl Acad Sci U S A. 2017;114:5195-200

37. Cheng F, Shen Y, Mohanasundaram P, Lindstrom M, Ivaska J, Ny T, Eriksson JE. Vimentin coordinates fibroblast proliferation and keratinocyte differentiation in wound healing via TGF-beta-slug signaling. Proc Natl Acad Sci U S A. 2016;113:E4320-7.

38. Maier J, Traenkle B, Rothbauer U. Visualizing epithelial-mesenchymal transition using the Chromobody technology. Cancer Res. 2016;76:5592-6.

39. Forest E, Logeay R, Geminard C, Kantar D, Frayssinoux F, Heron-Milhavet L, Djiane A. The apical scaffold big bang binds to spectrins and regulates the growth of Drosophila melanogaster wing discs. J Cell Biol. 2018;217(3): 1047-62.

40. Chugh P, Clark AG, Smith MB, Cassani DAD, Dierkes K, Ragab A, Roux PP, Charras G, Salbreux G, Paluch EK. Actin cortex architecture regulates cell surface tension. Nat Cell Biol. 2017;19:689-97.

41. Petrie RJ, Doyle AD, Yamada KM. Random versus directionally persistent cell migration. Nat Rev Mol Cell Biol. 2009;10:538-49.

42. Yamaguchi $\mathrm{H}$, Condeelis J. Regulation of the actin cytoskeleton in cancer cell migration and invasion. Biochim Biophys Acta. 2007;1773:642-52.

43. Faix J, Grosse R. Staying in shape with formins. Dev Cell. 2006;10:693-706.

44. Cojoc D, Difato F, Ferrari E, Shahapure RB, Laishram J, Righi M, Di Fabrizio EM, Torre V. Properties of the force exerted by filopodia and lamellipodia and the involvement of cytoskeletal components. PLoS One. 2007;2:e1072.

45. Mattila PK, Lappalainen P. Filopodia: molecular architecture and cellular functions. Nat Rev Mol Cell Biol. 2008;9:446-54

46. Murphy DA, Courtneidge SA. The 'ins' and 'outs' of podosomes and invadopodia: characteristics, formation and function. Nat Rev Mol Cell Biol. 2011;12:413-26.

47. Jerrell RJ, Parekh A. Cellular traction stresses mediate extracellular matrix degradation by invadopodia. Acta Biomater. 2014;10:1886-96.

48. Moore SW, Roca-Cusachs P, Sheetz MP. Stretchy proteins on stretchy substrates: the important elements of integrin-mediated rigidity sensing. Dev Cell. 2010;19:194-206.

49. Araki K, Ebata T, Guo AK, Tobiume K, Wolf SJ, Kawauchi K. p53 regulates cytoskeleton remodeling to suppress tumor progression. Cell Mol Life Sci. 2015;72:4077-94.
50. Lv M, Zhong Z, Huang M, Tian Q, Jiang R, Chen J. IncRNA H19 regulates epithelial-mesenchymal transition and metastasis of bladder cancer by miR29b-3p as competing endogenous RNA. Biochim Biophys Acta. 2017;1864: 1887-99.

51. Zheng P, Xiong Q, Wu Y, Chen Y, Chen Z, Fleming J, Gao D, Bi L, Ge F. Quantitative proteomics analysis reveals novel insights into mechanisms of action of long noncoding RNA Hox transcript antisense intergenic RNA (HOTAIR) in HeLa cells. Mol Cell Proteomics. 2015;14:1447-63.

52. Chen R, Kong P, Zhang F, Shu YN, Nie X, Dong LH, Lin YL, Xie XL, Zhao LL, Zhang XJ, Han M. EZH2-mediated alpha-actin methylation needs IncRNA TUG1, and promotes the cortex cytoskeleton formation in VSMCs. Gene. 2017;616:52-7.

53. Huang JF, Guo YJ, Zhao CX, Yuan SX, Wang Y, Tang GN, Zhou WP, Sun SH. Hepatitis $B$ virus $X$ protein ( $H B X$ )-related long noncoding RNA (IncRNA) down-regulated expression by HBx (Dreh) inhibits hepatocellular carcinoma metastasis by targeting the intermediate filament protein vimentin. Hepatology. 2013;57:1882-92.

54. Chen QN, Chen X, Chen ZY, Nie FQ, Wei CC, Ma HW, Wan L, Yan S, Ren SN, Wang ZX. Long intergenic non-coding RNA 00152 promotes lung adenocarcinoma proliferation via interacting with EZH2 and repressing IL24 expression. Mol Cancer. 2017;16:17.

55. Muller S, Raulefs S, Bruns P, Afonso-Grunz F, Plotner A, Thermann R, Jager C Schlitter AM, Kong B, Regel I, Roth WK, Rotter B, Hoffmeier K, Kahl G, Koch I, Theis FJ, et al. Next-generation sequencing reveals novel differentially regulated mRNAs, IncRNAs, miRNAs, sdRNAs and a piRNA in pancreatic cancer. Mol Cancer. 2015:14:94.

56. Zhang YH, Fu J, Zhang ZJ, Ge CC, Yi Y. LncRNA-LINC00152 down-regulated by miR-376c-3p restricts viability and promotes apoptosis of colorectal cancer cells. Am J Transl Res. 2016:8:5286-97.

57. Cai Q, Wang Z, Wang S, Weng M, Zhou D, Li C, Wang J, Chen E, Quan Z. Long non-coding RNA LINC00152 promotes gallbladder cancer metastasis and epithelial-mesenchymal transition by regulating HIF-1alpha via miR-138. Open Biol. 2017;7

58. Yue B, Cai D, Liu C, Fang C, Yan D. Linc00152 functions as a competing endogenous RNA to confer Oxaliplatin resistance and holds prognostic values in Colon Cancer. Mol Ther. 2016;24:2064-77.

59. Chen WM, Huang MD, Sun DP, Kong R, Xu TP, Xia R, Zhang EB, Shu YQ. Long intergenic non-coding RNA 00152 promotes tumor cell cycle progression by binding to EZH2 and repressing p15 and p21 in gastric cancer. Oncotarget. 2016;7:9773-87.

60. Van Grembergen $\mathrm{O}$, Bizet $\mathrm{M}$, de Bony EJ, Calonne E, Putmans P, Brohee S, Olsen C, Guo M, Bontempi G, Sotiriou C, Defrance M, Fuks F. Portraying breast cancers with long noncoding RNAs. Sci Adv. 2016;2: e1600220.

61. Ji J, Tang J, Deng L, Xie Y, Jiang R, Li G, Sun B. LINC00152 promotes proliferation in hepatocellular carcinoma by targeting EpCAM via the mTOR signaling pathway. Oncotarget. 2015;6:42813-24.

62. Wakatsuki T, Wysolmerski RB, Elson EL. Mechanics of cell spreading: role of myosin II. J Cell Sci. 2003;116:1617-25.

63. Sarbassov DD, Ali SM, Kim DH, Guertin DA, Latek RR, Erdjument-Bromage $H_{\text {, }}$ Tempst $P$, Sabatini DM. Rictor, a novel binding partner of $\mathrm{mTOR}$, defines a rapamycin-insensitive and raptor-independent pathway that regulates the cytoskeleton. Curr Biol. 2004;14:1296-302.

64. Scott KL, Kabbarah O, Liang MC, Ivanova E, Anagnostou V, Wu J, Dhakal S, Wu M, Chen S, Feinberg T, Huang J, Saci A, Widlund HR, Fisher DE, Xiao Y, Rimm DL, et al. GOLPH3 modulates mTOR signalling and rapamycin sensitivity in cancer. Nature. 2009;459:1085-90.

65. Satelli A, Li S. Vimentin in cancer and its potential as a molecular target for cancer therapy. Cell Mol Life Sci. 2011;68:3033-46.

66. Ono $H$, Motoi $N$, Nagano $H$, Miyauchi E, Ushijima M, Matsuura M, Okumura S, Nishio M, Hirose T, Inase N, Ishikawa Y. Long noncoding RNA HOTAIR is relevant to cellular proliferation, invasiveness, and clinical relapse in smallcell lung cancer. Cancer Med. 2014;3:632-42.

67. Wu XC, Wang SH, Ou HH, Zhu B, Zhu Y, Zhang Q, Yang Y, Li H. The NmrAlike family domain containing 1 pseudogene Loc344887 is amplified in gallbladder cancer and promotes epithelial-mesenchymal-transition. Chem Biol Drug Des. 2017;90(3):456-63.

68. Xu Y, Wang B, Zhang F, Wang A, Du X, Hu P, Zhu Y, Fang Z. Long non-coding RNA CCAT2 is associated with poor prognosis in hepatocellular carcinoma and promotes tumor metastasis by regulating Snail2-mediated epithelial-mesenchymal transition. Onco Targets Ther. 2017:10:1191-8. 
69. Gruenbaum Y, Aebi U. Intermediate filaments: a dynamic network that controls cell mechanics. F1000Prime Rep. 2014;6:54.

70. Wang Y, He H, Li W, Phay J, Shen R, Yu L, Hancioglu B, de la Chapelle A. MYH9 binds to IncRNA gene PTCSC2 and regulates FOXE1 in the 9q22 thyroid cancer risk locus. Proc Natl Acad Sci U S A. 2017;114:474-9.

71. Press JZ, Reyes M, Pitteri SJ, Pennil C, Garcia R, Goff BA, Hanash SM, Swisher EM. Microparticles from ovarian carcinomas are shed into ascites and promote cell migration. Int J Gynecol Cancer. 2012;22:546-52.

72. Zhao X, Wang P, Liu J, Zheng J, Liu Y, Chen J, Xue Y. Gas5 exerts tumorsuppressive functions in human glioma cells by targeting miR-222. Mol Ther. 2015:23:1899-911.

73. Lappalainen $P$, Drubin DG. Cofilin promotes rapid actin filament turnover in vivo. Nature. 1997;388:78-82

74. Xue M, Pang H, Li X, Li H, Pan J, Chen W. Long non-coding RNA urothelial cancer-associated 1 promotes bladder cancer cell migration and invasion by way of the hsa-miR-145-ZEB1/2-FSCN1 pathway. Cancer Sci. 2016;107:18-27.

75. Parsons M, Adams JC. Rac regulates the interaction of fascin with protein kinase C in cell migration. J Cell Sci. 2008;121:2805-13.

76. Vignjevic D, Kojima S, Aratyn Y, Danciu O, Svitkina T, Borisy GG. Role of fascin in filopodial protrusion. J Cell Biol. 2006;174:863-75.

77. Burridge K, Wennerberg K. Rho and Rac take center stage. Cell. 2004;116: 167-79.

78. Amano M, Nakayama M, Kaibuchi K. Rho-kinase/ROCK: a key regulator of the cytoskeleton and cell polarity. Cytoskeleton (Hoboken). 2010;67:545-54.

79. Symons M. Rho family GTPases: the cytoskeleton and beyond. Trends Biochem Sci. 1996;21:178-81.

80. Etienne-Manneville S, Hall A. Rho GTPases in cell biology. Nature. 2002;420: 629-35.

81. Pruitt K, Ras DCJ. Rho regulation of the cell cycle and oncogenesis. Cancer Lett. 2001:171:1-10.

82. Jaffe $A B$, Hall A. Rho GTPases: biochemistry and biology. Annu Rev Cell Dev Biol. 2005;21:247-69.

83. Joshi B, Strugnell SS, Goetz JG, Kojic LD, Cox ME, Griffith OL, Chan SK, Jones SJ, Leung SP, Masoudi H, Leung S, Wiseman SM, Nabi IR. Phosphorylated caveolin-1 regulates rho/ROCK-dependent focal adhesion dynamics and tumor cell migration and invasion. Cancer Res. 2008;68:8210-20.

84. Garcia-Mariscal A, Li H, Pedersen E, Peyrollier K, Ryan KM, Stanley A, Quondamatteo F, Brakebusch C. Loss of RhoA promotes skin tumor formation and invasion by upregulation of RhoB. Oncogene. 2018;37:847-60.

85. Alkasalias T, Alexeyenko A, Hennig K, Danielsson F, Lebbink RJ, Fielden M, Turunen SP, Lehti K, Kashuba V, Madapura HS, Bozoky B, Lundberg E, Balland M, Guven H, Klein G, Gad AK, et al. RhoA knockout fibroblasts lose tumor-inhibitory capacity in vitro and promote tumor growth in vivo. Proc Natl Acad Sci U S A. 2017;114:E1413-21.

86. Egami Y, Kawai K, Araki N. RhoC regulates the actin remodeling required for phagosome formation during FcgammaR-mediated phagocytosis. J Cell Sci. 2017:130:4168-79.

87. Chuang YY, Tran NL, Rusk N, Nakada M, Berens ME, Symons M. Role of synaptojanin 2 in glioma cell migration and invasion. Cancer Res. 2004;64: 8271-5.

88. Arana E, Vehlow A, Harwood NE, Vigorito E, Henderson R, Turner M, Tybulewicz VL, Batista FD. Activation of the small GTPase Rac2 via the B cell receptor regulates $B$ cell adhesion and immunological-synapse formation. Immunity. 2008;28:88-99.

89. Donnelly SK, Cabrera R, Mao SPH, Christin JR, Wu B, Guo W, Bravo-Cordero $J$ J, Condeelis JS, Segall JE, Hodgson L. Rac3 regulates breast cancer invasion and metastasis by controlling adhesion and matrix degradation. J Cell Biol. 2017;216:4331-49.

90. Richerioux N, Blondeau C, Wiedemann A, Remy S, Vautherot JF, Denesvre C. Rho-ROCK and Rac-PAK signaling pathways have opposing effects on the cell-to-cell spread of Marek's disease virus. PLoS One. 2012;7:e44072.

91. Riento K, Villalonga P, Garg R, Ridley A. Function and regulation of RhoE. Biochem Soc Trans. 2005:33:649-51

92. Pinner S, Sahai E. PDK1 regulates cancer cell motility by antagonising inhibition of ROCK1 by RhoE. Nat Cell Biol. 2008;10:127-37.

93. Riento K, Ridley A. Rocks: multifunctional kinases in cell behaviour. Nat Rev Mol Cell Biol. 2003;4:446-56.

94. Rath N, Morton JP, Julian L, Helbig L, Kadir S, McGhee EJ, Anderson KI, Kalna G, Mullin M, Pinho AV, Rooman I, Samuel MS, Olson MF. ROCK signaling promotes collagen remodeling to facilitate invasive pancreatic ductal adenocarcinoma tumor cell growth. EMBO Mol Med. 2017;9:198-218.
95. Newell-Litwa KA, Badoual M, Asmussen H, Patel H, Whitmore L, Horwitz AR. ROCK1 and 2 differentially regulate actomyosin organization to drive cell and synaptic polarity. J Cell Biol. 2015;210:225-42.

96. Jerrell RJ, Parekh A. Matrix rigidity differentially regulates invadopodia activity through ROCK1 and ROCK2. Biomaterials. 2016;84:119-29.

97. Jerrell RJ, Leih MJ, Parekh A. The ROCK isoforms differentially regulate the morphological characteristics of carcinoma cells. Small GTPases. 2017:1-7.

98. Darenfed H, Dayanandan B, Zhang T, Hsieh SH, Fournier AE, Mandato CA. Molecular characterization of the effects of Y-27632. Cell Motil Cytoskeleton. 2007:64:97-109.

99. Jansen S, Gosens R, Wieland T, Schmidt M. Paving the rho in cancer metastasis: rho GTPases and beyond. Pharmacol Ther. 2018;183:1-21.

100. Sun CX, Magalhaes MA, Glogauer M. Rac1 and Rac2 differentially regulate actin free barbed end formation downstream of the fMLP receptor. J Cell Biol. 2007;179:239-45.

101. Pellegrin S, Mellor H. The rho family GTPase Rif induces filopodia through mDia2. Curr Biol. 2005;15:129-33.

102. Ridley AJ. Life at the leading edge. Cell. 2011;145:1012-22.

103. Lizarraga F, Poincloux R, Romao M, Montagnac G, Le Dez G, Bonne I, Rigaill G, Raposo G, Chavrier P. Diaphanous-related formins are required for invadopodia formation and invasion of breast tumor cells. Cancer Res. 2009;69:2792-800.

104. Semprucci E, Tocci P, Cianfrocca R, Sestito R, Caprara V, Veglione M, Castro VD, Spadaro F, Ferrandina G, Bagnato A, Rosano L. Endothelin a receptor drives invadopodia function and cell motility through the beta-arrestin/ PDZ-RhoGEF pathway in ovarian carcinoma. Oncogene. 2016;35:3432-42.

105. Poincloux R, Lizarraga F, Chavrier P. Matrix invasion by tumour cells: a focus on MT1-MMP trafficking to invadopodia. J Cell Sci. 2009;122:3015-24.

106. Sakurai-Yageta M, Recchi C, Le Dez G, Sibarita JB, Daviet L, Camonis J, D'Souza-Schorey C, Chavrier P. The interaction of IQGAP1 with the exocyst complex is required for tumor cell invasion downstream of Cdc42 and RhoA. J Cell Biol. 2008;181:985-98.

107. Cai X, Liu Y, Yang W, Xia Y, Yang C, Yang S, Liu X. Long noncoding RNA MALAT1 as a potential therapeutic target in osteosarcoma. J Orthop Res. 2016;34:932-41.

108. Chou J, Wang B, Zheng T, Li X, Zheng L, Hu J, Zhang Y, Xing Y, Xi T. MALAT1 induced migration and invasion of human breast cancer cells by competitively binding miR-1 with cdc42. Biochem Biophys Res Commun. 2016:472:262-9.

109. Tang Y, He Y, Shi L, Yang L, Wang J, Lian Y, Fan C, Zhang P, Guo C, Zhang S, Gong Z, Li X, Xiong F, Li X, Li Y, Li G, Xiong W, Zeng Z. Co-expression of AFAP1-AS1 and PD-1 predicts poor prognosis in nasopharyngeal carcinoma. Oncotarget. 2017; 8(24):39001-11.

110. Wang C, Yan G, Zhang Y, Jia X, Bu P. Long non-coding RNA MEG3 suppresses migration and invasion of thyroid carcinoma by targeting of Rac1. Neoplasma. 2015;62:541-9.

111. Shi S, Peng Q, Shao X, Xie J, Lin S, Zhang T, Li Q, Li X, Lin Y. Self-assembled tetrahedral DNA nanostructures promote adipose-derived stem cell migration via IncRNA XLOC 010623 and RHOA/ROCK2 signal pathway. ACS Appl Mater Interfaces. 2016;8:19353-63.

112. Ge Z, Cheng Z, Yang X, Huo X, Wang N, Wang H, Wang C, Gu D, Zhao F, Yao M, Fan J, Qin W. Long noncoding RNA SchLAH suppresses metastasis of hepatocellular carcinoma through interacting with fused in sarcoma. Cancer Sci. 2017;108:653-62.

113. Tang Y, Wang J, Lian Y, Fan C, Zhang P, Wu Y, Li X, Xiong F, Li X, Li G, Xiong W, Zeng Z. Linking long non-coding RNAs and SWI/SNF complexes to chromatin remodeling in cancer. Mol Cancer. 2017;16(1):42.

114. Wu D, Chen X, Sun K, Wang L, Chen S, Zhao Y. Role of the IncRNA ABHD11AS1 in the tumorigenesis and progression of epithelial ovarian cancer through targeted regulation of RhoC. Mol Cancer. 2017;16:138. 